annotation of this specialised area which might be of practical use to paediatricians with a general interest in haematology. The emphasis is therefore on current concepts of donor selection and recent results.

Regrettably in this type of communication there is no space to address interesting historical perspective such as that provided by the Westminster team. Their experience would certainly take pride of place in a full length review article.

\section{District handicap teams: impediments to} progress

SIR, - Of the reasons discussed by Bax and Whitmore for lack of progress in setting up Court type district handicap teams, ${ }^{1}$ much the most important is the inability or unwillingness of many doctors to contribute to effective interdisciplinary work. Education and social service departments are reluctant to commit resources to child development centres, especially those on hospital sites, because they anticipate medical domination of operational policy (referrals, etc), day to day management, and 'patient care' decision making. It would take much more than a 'commitment to provide a peripatetic service in satellite premises' to offset these reservations.

Similarly, professionals employed by education and social services are disinclined to recognise a divine right of doctors to be in charge under all circumstances, and are unlikely to work with enthusiasm in such an environment. A senior social worker, himself committed to interdisciplinary working, said to me recently, 'a doctor's definition of a team is a group of people working together whom he/she (the doctor) tells what to do'. The joke is on us, but it is really not at all funny.

Bax and Whitmore think that the Court committee's concept of a district handicap team was sound: I agree (I was a member of the committee) in the historical context of the late 1970s. Much has happened since then, however, and the changes in thinking and practice reflected in the Education Act 1981 the Disabled Persons' Act 1986, and the Children Act 1989 require that responsibilities for the management of childhood disability are shared far beyond the health services terms of reference of the Court committee. Of course the medical and health related contribution continues to be crucial and even pivotal in many instances, especially in early childhood. Unless we collectively are more whole hearted and less professionally arrogant in our attitude to interdisciplinary work, however, our influence will increasingly be marginalised. We risk being consulted rather than involved, which would jeopardise comprehensive care: the ultimate losers would be the children and their families.

The child development centre is a medical model (for example, in siting and referral procedures), and therefore inappropriate on its own for the 1990s. Bax and Whitmore also acknowledge some of the problems of trying to cater for children of all ages in a single centre. How indeed do you combine suitable decor, furniture, equipment, and comprehensive service provision for infants and toddlers, preschool and school children, and adolescents all under one affordable roof?

I suggest that the way ahead is to develop a suitably updated concept of teams which work flexibly in different contexts and premises, one of which might well be a 'centre' on hospital site where facilities for early medical identification and diagnosis are linked with the initial stages of treatment and ongoing assessment.

Interagency discussions about the Children Act present us now with excellent new opportunities to create or reinforce effective teamwork. Doctors involved in this collaboration need to be sure that they do not take any pedestals with them.

MICHAEL ROGERS Royal Liverpool Children's Hospital, Myrtle Street,
Liverpool L 7 7DG 1 Bax MCO, Whitmore K. District handicap teams
in England: 1983-8. Arch Dis Child 1991;66: 656-64.

\section{District handicap teams in England 1983-8}

SIR,-We wish to make it clear that in our article on district handicap teams ${ }^{1}$ our third recommendation (p664) is that the child development centre should initially be able to cater for the needs of all children under 16 years (not under 10 as stated) and for older children in the absence of adequate similar facilities for disabled adolescents.

\section{C O BAX \\ $K$ WHITMORE \\ Community Paediatric Research Unit, Westminster Children's Hospital,}

Vincent Square, London SWIP $2 N S$

1 Bax MCO, Whitmore K. District handicap teams in England: 1983-8. Arch Dis Child 1991;66: in England.

\section{Major problems with paediatric bed usage} statistics?

SIR,-MacFaul and Long show that paediatric bed occupancy in two children's wards in Pinderfields Hospital can be calculated in five different ways, giving results ranging from $73 \%$ to $106 \%$, depending on the treatment of empty beds and bed borrowing between specialties. ${ }^{1}$

Interesting as the exercise is, Dr MacFaul and Mr Long might ask their district management why such calculations should be necessary. The Körner committee recommended in 1982 that empty beds should no longer be allocated to a specialty. ${ }^{2}$ Allocation of beds to specialties should be seen as statement of operational planning intent and does not have to correspond to beds physically occupied or unoccupied, counted on a daily basis. $^{3}$

Because of flexible use of beds between specialties, it is necessary to distinguish between ward bed occupancy and specialty bed occupancy. Ward occupancy is calculated as:

occupied bed days in ward

available bed days in ward

for each ward. This gives, as McFaul and Long show, $54 \%$ for ward A and $69 \%$ for ward $B$ in their example. Specialty occupancy is calculated as:

\section{occupied bed days in any ward}

allocated bed days for specialty

In the Pinderfields example, on the information given, this is:
949 (ward A) + 3074 (ward B) + 201 (intensive care and other)

\section{7 (allocated to paediatrics)}

giving a paediatric bed occupancy over the period shown of $81 \%$. This method follows not only 'the spirit of Körner', but also the letter.

This level of occupancy is well above the optimum of $75 \%$ for acute children's services mentioned in Health Building Note $23^{4}$ and supports concerns about a possible shortage of capacity to deal with peaks in demand. MYER GLICKMAN
Child Health Monitoring Unit, Department of Paediatric Epidemiology, Institute of Child Health, London WCIN IEH

1 MacFaul R, Long R. Major problems with paediatric bed usage statistics? Arch Dis Child 1991;66:504-7.

2 Steering Group on Health Services Information (Körner Committee). First Report to the Secretary of State: a report on the collection and use of of State: a report on the collection and use of
information about hospital clinical activity in the information about hospital clinical action

3 Health Services Information Branch. User's guide to statistics about the clinical activity of departments and services provided on or off a hospital ments and services provided on or off a hospital site. London: Department of Health, 1988:173.
Department of Health and Social Security. 4 Department of Health and Social Security. Health building note 23: hospital accom
for children. London: DHSS, 1984.

\section{Dr MacFaul and Mr Long comment:}

We thank Mr Glickman for his helpful comments on our paper. It is indeed the case that the Körner committee recommended that it should no longer be required that unoccupied beds be attributed to a specialty. Furthermore, it was recommended that bed occupancy statistics cease to be used as a measure of efficient bed usage (Körner first report para 9.39.) $)^{1}$ However, in Yorkshire Regional Health Authority, bed occupancy measures were reintroduced in response to demand from health authorities: hence the development of the modified SH3 (YSH3B) referred to in our paper. It is a concept with which clinicians are familiar and bed occupancy possibly identifies more readily shortfall of specialty paediatric bed allocation over peak bed usage periods. Hence it was used in this paper. One main point of the paper, however, was to identify the variation in interpretation of Körner recommendations which may occur within a district-thereby limiting the value of between-district indicators. Mr Glickman's calculation of occupancy disregards, as Körner advised, any allocation of empty beds to a specialty but he does necessarily include the nominal allocation of beds for use by the specialty. Such allocation is also necessary to calculate throughput (throughput is calculated in terms of number of beds that the specialty was intended to use, rather than the beds estimated to be available). For patients with the same length of stay during the study period report in our paper, throughput figures varied considerably (between 23.83 and 34.68 ) according to the way in which the notional allocation of beds was made between two wards. The throughput figures based on the calculations used by $\mathrm{Mr}$ Glickman are given in option (1) in our paper.

Using the maximum flexibility-our option (5)-the highest throughput and bed occupancy figures were achieved. This maximum flexibility of usage seems more clearly to be in the spirit of Körner. A further and most important point evident from the study was the significance of when, in the 24 hou 
period, a count of patients was made and how complete such a count proved to be.

Since the recommendation made in the Health Building Note 23 in 1984, there has been steadily decreasing duration of stay in paediatric medicine. It is not clear what an optimal bed occupancy or throughput should be in order to be able to achieve adequate capacity to accommodate children in children wards over peak periods of usage.

1 Körner E, chairman. NHS/DHSS steering group on health services information. First report. London: DHSS, 1982.

\section{Neonatal diaphragmatic paralysis caused by} chest drains

SIR,-Arya et al attributed bilateral phrenic nerve palsy to the insertion of chest drains. Although they elegantly proved dysfunction in both phrenic nerves, they provided no evidence of a causative association with the insertion of the chest drains.

Both phrenic nerves are closely related to major vessels and the pericardium within the mediastinum ${ }^{2}$ and therefore damage affecting the phrenic nerves alone would seem unlikely.

An alternative explanation would be stretching of the phrenic nerve caused by a tension pneumothorax increasing the distance from the nerves' origin to its insertion.

Finally it would not seem very likely for a process which is very uncommon, only having been described on two previous occasions, to occur twice in the same patient.

Surely it is dangerous to attribute events to an iatrogenic cause, with the possible implications of this, when an alternative explanation involving the natural history of the underlying disease is possible.

STEPHEN W JONES
Royal United Hospital,
Combe Park,
Bath BAl $3 N G$

1 Arya $\mathrm{H}$, Williams J, Ponsford SN, Bissenden JG. Neonatal diaphragmatic paralysis caused by chest drains. Arch Dis Child 1991;66:441-2.

2 Williams PL, Warwick R, eds. Gray's anatomy. London: Churchill Livingstone, 1980.

\section{Dr Bissenden comments}

I would accept that our case report did not prove that chest drains caused the phrenic nerve damage. It merely demonstrated bilateral phrenic nerve paralysis in a baby who had chest drains which reached the mediastinum. We suggested the chest drains caused the problems in the absence of another explanation. The alternative suggestion that a tension pneumothorax caused the phrenic nerve damage of such duration is more unlikely than our explanation, so until someone comes up with something better, ours is the best I have heard so far.

\section{Children choking on foreign bodies from toys}

SIR,-There is interest in the problem of aspiration of foreign bodies from toys. Manufacturers and trading standards officers raise practical issues about the size of items that might cause choking, the risks of hair or pile fabrics on toys, and the attractiveness to children of items which might imitate food. It is not known how common these incidents are. This is relevant to the European Toy Safety Standard EN71, which is currently under review. Unfortunately the Departmen of Trade and Industry's Home Accident Surveillance System (HASS), which analyses a sample of cases attending accident and emergency departments does not provide satisfactory information. This is because choking is combined with ingestion and insertion of foreign bodies into body orifices under a general heading 'foreign bodies'.

We therefore undertook a study of incidents of choking in childhood for the year 1989 in Wales to estimate whether aspiration of foreign bodies from toys and toy parts was common. Letters were sent to all 60 consultant paediatricians and ear, nose, and throat surgeons in Wales asking them for details of children who were admitted to hospital after choking on foreign bodies. Replies were obtained from 50 consultants $(83 \%)$. Only four recalled any cases of choking, none of which was related to toys.

We also inquired whether the consultants had ever seen such an incident related to toys. Only one doctor recalled such an incident and this was due to a small bead. There were no instances of choking due to hair from a toy.

We conclude that incidents of choking due to parts or hair from toys must be rare and are not a major problem in the UK.

$$
\begin{array}{r}
\text { JEAN MATTHES } \\
\text { JO SIBERT } \\
\text { Department of Child Health, } \\
\text { University of Wales College of Medicine, } \\
\text { Llandough Hospital, Penarth, } \\
\text { South Glamorgan CF6 IXX } \\
\text { SARA LEVENE } \\
\text { Child Accident Prevention Trust, } \\
28 \text { Portland Place, }
\end{array}
$$

\section{Accidental poisoning in children}

SIR,-Drs Sibert and Routledge are correct. ${ }^{1}$ Childhood poisoning should be classified and managed according to the estimated intake and severity rating of the ingested toxin. Poisoning events might be classified as follows:

(1) Poisoning scare. Tablets or medicine spilt. No ingestion. Poisoning nonevent. Frequent.

(2) Minimal ingestion. Few $\mathrm{ml}$ or few tablets. No symptoms or signs. Common.

(3) Moderate ingestion. No apparent sequelae. Common.

(4) Severe ingestion. Toxic agent in significant amount. Infrequent.
We have found that use of observation beds in the casualty department is adequate for groups 1,2 , and 3 and resulted in a $74 \%$ reduction in admission rates between 1975 and $1980 .^{2}$ Our recent study of 206 ingestions showed that $75 \%$ of children suspected of ingesting drugs were given syrup of ipecacuanha, $3 \%$ had gastric lavage, and $18 \%$ received no treatment. ${ }^{3}$ Seventy one per cent of children were observed and discharged. Of the remainder, $25 \%$ were admitted to a medical ward and $4 \%$ to intensive care. Poison reference centres are usually staffed and briefed by adult orientated people. Their management advice is frequently excessive and interventional, based on adult experience of severe intentional overdose as compared with childhood accidental and usually trivial ingestion.

The bottom line in poisoning is to take care to treat children and chemicals with cautious respect, and, if in doubt, to admit and observe. Delayed release psychotherapeutic agents should be treated with particular caution.

Finally, should laburnum be classified as 'potentially very toxic'?

$$
\begin{array}{r}
\text { H RFIDAH } \\
\text { D GILL } \\
\text { Department of Paediatrics, } \\
\text { Royal College of Surgeons in Ireland, } \\
123 \text { St Stephen's Green, } \\
\text { Dublin 2 }
\end{array}
$$

1 Sibert JR, Routledge PA. Accidental poisoning in children: can we admit fewer children with in children: can we admit fewer child

2 Gill D. Changing pattern of poisoning in children $B M 7$ 1983;287:1468.

3 Rfidah H, Casey P. Tracey JA, Gill D. Child hood poisoning in Dublin. Irish Med $\mathcal{F} 1991$ (in press).

\section{Hyperexplexia or stiff baby syndrome}

SIR,-I am sure that other people will write to you to tell you that the spelling of the condition referred to recently in the journal is incorrect. ${ }^{1}$ It should be 'hyperekplexia', 'ekplexia' is the Greek for startle, whereas 'explexia' does not mean anything at all! The present article perpetuates mis-spelling that has appeared in several other contributions on this subject.

\section{S J WALLACE Department of Child Health, University Hospital of Wales, Heath Park, Cardiff CF 4 4XW}

1 Tohier C, Roze JC, David A, Veccierini MF, Renaud P, Mouzard A. Hyperexplexia or stiff baby syndrome. Arch Dis Child 1991;66:460-1.

The technical editor comments

The dictionary we use for the journal is Dorland's Illustrated Medical Dictionary, which is American; this gives the spelling as hyperexplexia. We do 'adjust' the spelling of words like apnea and anemia to conform with 'English' spelling but otherwise we try to follow Dorland's 'style'. 